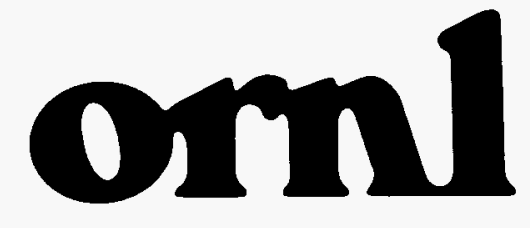

OAK RIDGE NATIONAL LABORATORY

MARTHN MARUETTA

\section{RECEIVED \\ MAR 131996 \\ OSTI}

\section{Radiation Effects in the Stainless Steel Primary Coolant Supply Adapter}

\author{
K. Farrell
}

September 1995

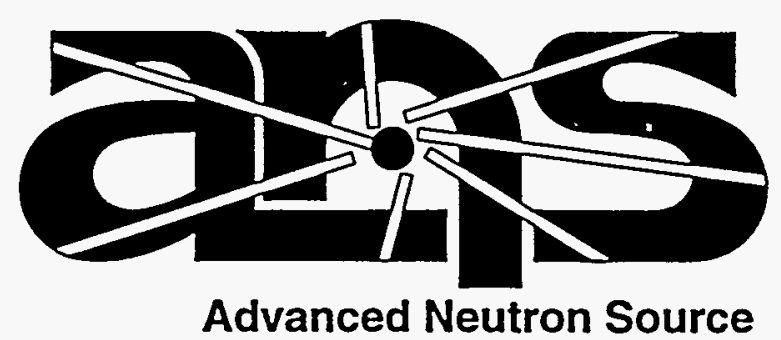

MANAGED BY

MARTIN MARIETTA ENERGY SYSTEMS, INC. FOR THE UHITED STATES DEPARTMENT OF ENERGY 
This report has been reproduced directly from the best available copy.

Available to DOE and DOE contractors from the Office of Scientific and Technical Information, P.O. Box 62, Oak Ridge, TN 37831; prices available from (615) 576-8401, FTS 626-8401.

Available to the public from the National Technical Information Service, U.S. Department of Commerce, 5285 Port Royal Rd., Springfield, VA 22161.

This report was prepared as an account of work sponsored by an agency of the United States Government. Neither the United States Government nor any agency thereof, nor any of their employees, makes any warranty, express or implied, or assumes any legal liability or responsibility for the accuracy, completeness, or usefuiness of any information, apparatus, product, or process disclosed, or represents that its use would not infringe privately owned rights. Reference herein to any specific commercial product, process, or service by trade name, trademark, manufacturer, or otherwise, does not necessarily constitute or imply its endorsement, recommendation, or favoring by the United States Government or any egency thereof. The views and opinions of authors expressed herein do not necessarily state or reflect those of the United States Government or any agency thereof. 


\title{
RADIATION EFFECTS IN THE STAINLESS STEEL PRIMARY COOLANT SUPPLY ADAPTER
}

K. Farrell

\section{September 1995}

\author{
Prepared by \\ OAK RIDGE NATIONAL LABORATORY \\ Oak Ridge, Tennessee 37831 \\ managed by \\ LOCKHEED MARTIN ENERGY SYSTEMS, INC. \\ for the \\ U.S. DEPARTMENT OF ENERGY \\ under contract DE-AC05-84OR21400
}




\section{CONTENTS}

ACRONYMS $\ldots \ldots \ldots \ldots \ldots \ldots \ldots \ldots \ldots \ldots \ldots \ldots \ldots \ldots \ldots \ldots \ldots$

ACKNOWLEDGEMENT $\ldots \ldots \ldots \ldots \ldots \ldots \ldots \ldots \ldots \ldots \ldots \ldots \ldots \ldots \ldots$ vii

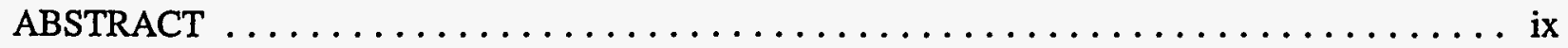

1. INTRODUCTION $\ldots \ldots \ldots \ldots \ldots \ldots \ldots \ldots \ldots \ldots \ldots \ldots \ldots \ldots \ldots \ldots \ldots$

2. MATERIAL $\ldots \ldots \ldots \ldots \ldots \ldots \ldots \ldots \ldots \ldots \ldots \ldots \ldots \ldots \ldots \ldots \ldots \ldots$

3. EXPOSURE CONDITIONS $\ldots \ldots \ldots \ldots \ldots \ldots \ldots \ldots \ldots \ldots \ldots \ldots \ldots \ldots \ldots$

4. DAMAGE ASSESSMENT $\ldots \ldots \ldots \ldots \ldots \ldots \ldots \ldots \ldots \ldots \ldots \ldots \ldots \ldots \ldots$

5. SHIELD EFFECTIVENESS $\ldots \ldots \ldots \ldots \ldots \ldots \ldots \ldots \ldots \ldots \ldots \ldots \ldots \ldots$

6. CONCLUSIONS $\ldots \ldots \ldots \ldots \ldots \ldots \ldots \ldots \ldots \ldots \ldots \ldots \ldots \ldots \ldots \ldots$

7. REFERENCES ............................... 11 


\section{ACRONYMS}

$\begin{array}{ll}\text { ANS } & \text { Advanced Neutron Source } \\ \text { appm } & \text { atomic parts per million } \\ \text { CPBT } & \begin{array}{l}\text { core pressure boundary tube } \\ \text { displacements per atom }\end{array} \\ \text { dpa } & \text { High Flux Isotope Reactor } \\ \text { HFIR } & \text { irradiation-assisted stress-corrosion cracking } \\ \text { IASCC } & \text { primary coolant supply adapter } \\ \text { PCSA } & \text { ultimate tensile strength } \\ \text { UTS } & \text { yield strength }\end{array}$




\section{ACKNOWLEDGEMENT}

The cooperation of Janet E. Pawel and the data base she manages for the Fusion Materials Program at Oak Ridge National Laboratory are much appreciated. 


\begin{abstract}
The primary coolant supply adapter (PCSA) is a flanged, cylindrical collar of 316NG stainless steel that is part of the primary pressure boundary of the Advanced Neutron Source. The radiation fluxes on the PCSA are dominated by thermal neutrons. During its intended 40-year service life, the PCSA will receive a thermal neutron fluence of $1.8 \times 10^{26} \mathrm{~m}^{-2}$ in its upper sections at a temperature of $<100^{\circ} \mathrm{C}$. The PCSA will suffer radiation damage, caused primarily by the interaction of thermal neutrons with the $14 \%$ nickel in the steel, which will generate helium by the sequential reactions ${ }^{58} \mathrm{Ni}$ $(\mathrm{n}, \gamma)^{59} \mathrm{Ni}(\mathrm{n}, \alpha)^{56} \mathrm{Fe}$ and will concurrently produce significant atomic displacements per atom (dpa) from the ${ }^{59} \mathrm{Ni}(n, \alpha)^{56} \mathrm{Fe}$ recoils. It is estimated that the helium concentration and total atomic displacements in the upper parts of the PCSA will be about 430 atomic parts per million and $1 \mathrm{dpa}$, respectively. From newly compiled trend curves of tensile properties and fracture toughness data versus atomic displacements for 316 steel, it is deduced that the irradiated PCSA will retain at least $20 \%$ uniform tensile elongation and a fracture toughness of more than $200 \mathrm{Mpa} \sqrt{\mathrm{m}}$, which are judged adequate to resist brittle failure. Therefore, employment of a neutron shield around the PCSA is unnecessary.
\end{abstract}





\section{INTRODUCTION}

The primary coolant supply adapter (PCSA) is a flanged, cylindrical collar that connects the primary coolant inlet manifold to the bottom of the core pressure boundary tube (CPBT) in the Advanced Neutron Source (ANS) reactor. It is located at the outside bottom of the reflector vessel at its junction with the CPBT, as shown in Fig. 1. The PCSA encircles the bottom of the 256-mm-diam CPBT, and the upper face of its flange abuts the outside bottom of the vessel. The lower part of the adapter projects $-190 \mathrm{~mm}$ below the bottom of the flange before meeting the manifold. Because the PCSA is a part of the primary pressure boundary of the reactor, it must be constructed from an ASME pressure code-approved material. It will be subjected to high rates of flow of acidified $\mathrm{D}_{2} \mathrm{O}$ coolant and therefore must be resistant to aqueous erosion and corrosion. The $316 \mathrm{NG}$ stainless steel meets these requirements and has been nominated as the PCSA material. The predominantly thermal neutron radiation fields on the adapter will create atomic displacements and transmutation products in the steel that will degrade its mechanical properties. A preliminary assessment indicated that radiation damage in the upper parts of the adapter might be severe enough to necessitate the use of shielding to reduce the thermal neutron flux on the adapter. ${ }^{1}$ At that time, an early model adapter was considered whose top stood $400 \mathrm{~mm}$ above the flange. The top of the present model adapter rises only $-190 \mathrm{~mm}$ above the 85-mm-thick flange, and therefore it will receive considerably smaller radiation fluxes than the older model. Also, more sophisticated flux calculations have reduced the flux levels in the vicinity of the adapter. ${ }^{2}$ This report reconsiders radiation damage in the PCSA in light of these changes.

\section{MATERIAL}

The nuclear-grade version of the common 316 alloy is $316 \mathrm{NG}$ austenitic stainless steel. It is an alloy of iron with a maximum of 0.02 wt \% carbon, 16 to $18 \%$ chromium, 10 to $14 \%$ nickel, 2 to $3 \%$ molybdenum, $2 \%$ manganese, and 0.06 to $0.10 \%$ nitrogen.

\section{EXPOSURE CONDITIONS}

The PCSA has an intended service life of 40 years. The coolant enters the manifold at a temperature of $45^{\circ} \mathrm{C}$, ensuring that the operating temperature of the adapter will be $<100^{\circ} \mathrm{C}$. The neutron spectrum at the adapter will be very strongly thermalized because of the moderation of neutrons in the $\mathrm{D}_{2} \mathrm{O}$ reflector. The estimated flux contour maps ${ }^{2}$ show the ratio of thermal flux to fast flux to be of order $10^{4}$. Specific values of fluxes interpolated from the maps for various locations on an unshielded PCSA and the corresponding fluences for a 40-year exposure at 0.7 duty factor are shown in Table 1.

The specific locations are the top of the adapter at its inner edge, the upper face of the flange at its outer edge, a ledge on the inside near the bottom, and a point on the inlet manifold $500 \mathrm{~mm}$ below the upper face of the flange. The fluxes, particularly for the upper parts of the adapter, are much smaller than those used earlier.'

\section{DAMAGE ASSESSMENT}

Three types of radiation effects are considered: radiation hardening with its associated loss in ductility, radiation creep, and irradiation-assisted stress-corrosion cracking (IASCC). IASCC is a 


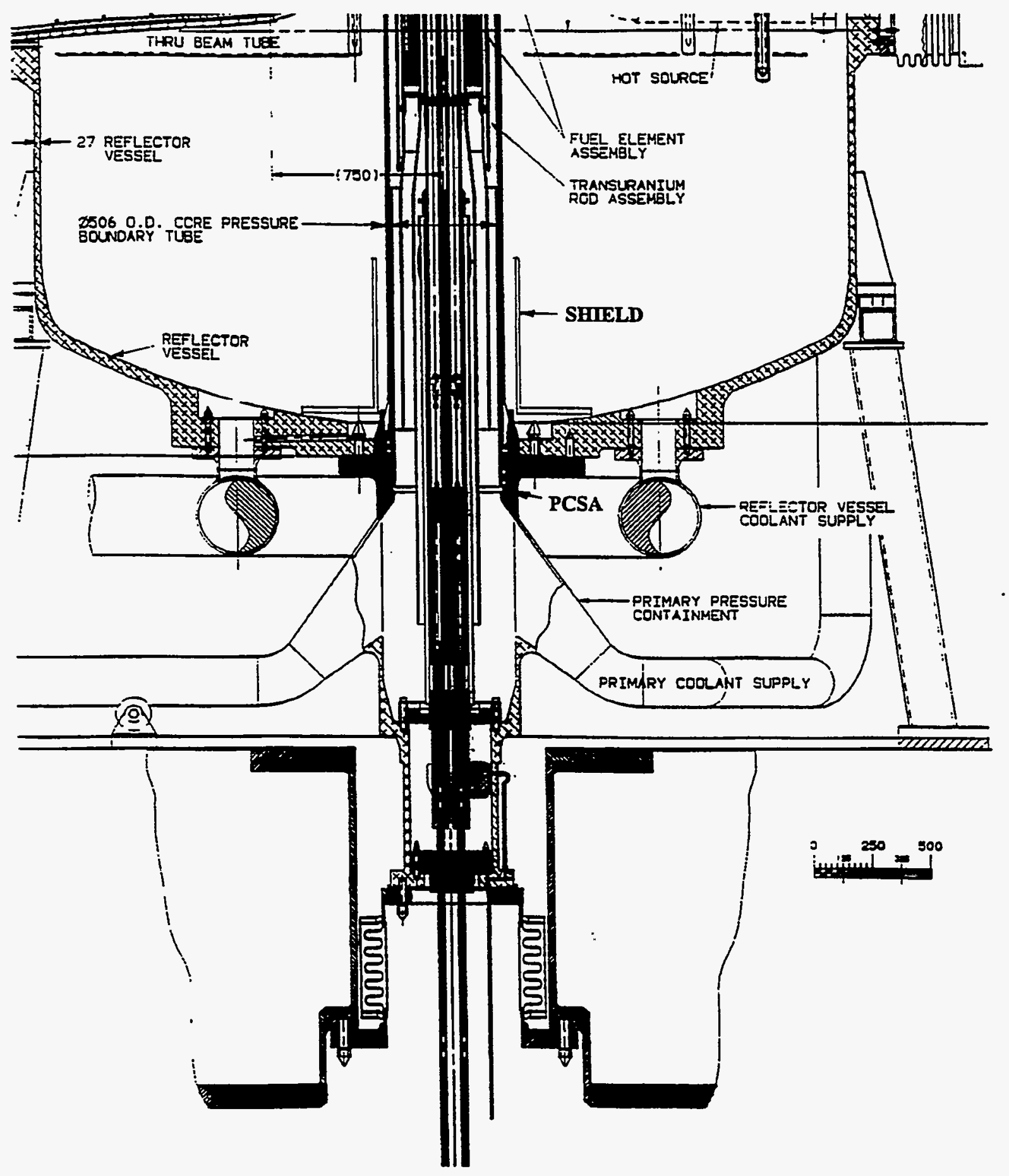

Fig. 1.1. Location of the PCSA. 
Table 1. Radiation fluxes and fluences for the PCSA

\begin{tabular}{|c|c|c|c|c|c|c|}
\hline \multirow[b]{2}{*}{ Location } & \multicolumn{3}{|c|}{$\begin{array}{c}\text { Fluxes } \\
\left(\mathrm{m}^{-2} \cdot \mathrm{s}^{-1}\right)\end{array}$} & \multicolumn{3}{|c|}{$\begin{array}{c}\text { Fluences } \\
\left(\mathrm{m}^{-2}\right)\end{array}$} \\
\hline & $\mathrm{E}>0.1 \mathrm{MeV}$ & $\mathrm{E}<0.625 \mathrm{eV}$ & $\mathrm{E} \gamma>2 \mathrm{MeV}$ & $\mathrm{E}>0.1 \mathrm{MeV}$ & $\mathrm{E}<0.625 \mathrm{eV}$ & $E \gamma>2 \mathrm{MeV}$ \\
\hline $\begin{array}{l}\text { Top of } \\
\text { adapter }\end{array}$ & 7E13 & $2 \mathrm{E} 17$ & $5 \mathrm{E} 16$ & $6.2 \mathrm{E} 22$ & $1.8 \mathrm{E} 26$ & 4.4E25 \\
\hline $\begin{array}{l}\text { Upper face } \\
\text { of flange }\end{array}$ & $1 \mathrm{E} 13$ & $1 \mathrm{E} 17$ & $2 \mathrm{E} 16$ & $8.8 \mathrm{E} 21$ & $8.8 \mathrm{E} 25$ & $1.8 \mathrm{E} 25$ \\
\hline $\begin{array}{l}\text { Bottom of } \\
\text { adapter }\end{array}$ & $1 E 13$ & $2 \mathrm{E} 15$ & 9E15 & $8.8 \mathrm{E} 21$ & $1.8 \mathrm{E} 24$ & $8 \mathrm{E} 24$ \\
\hline Manifold & $1 \mathrm{E} 12$ & $1 \mathrm{E} 14$ & $2 \mathrm{E} 15$ & $8.8 \mathrm{E} 20$ & $8.8 \mathrm{E} 22$ & $1.8 \mathrm{E} 24$ \\
\hline
\end{tabular}

serious problem of intergranular cracking that occurs in stainless steels irradiated in contact with water to doses greater than -0.5 displacements per atom (dpa) at $-290^{\circ} \mathrm{C}$ in light water power reactors. A characteristic feature of IASCC is the depletion of chromium atoms at grain boundaries driven by radiation-assisted migration of chromium solutes. IASCC is very similar to intergranular stresscorrosion cracking of unirradiated stainless steels whose grain boundaries have been sensitized by improper heat treatment. Lately, IASCC has cropped up in retired reactor components of stainless steel during storage in water at $-50^{\circ} \mathrm{C}$ after radiation exposure at $290^{\circ} \mathrm{C}$. Very recently IASCC has been reported in specimens tested in water at $290^{\circ} \mathrm{C}$ after irradiation in water at $-50^{\circ} \mathrm{C}$; depletion of chromium at grain boundaries was observed that must have occurred during the $50^{\circ} \mathrm{C}$ irradiation." This finding strongly suggests the possibility of IASCC's occurring in the PCSA during irradiation at $<100^{\circ} \mathrm{C}$. At present, there are no claims of IASCC in reactor components during service at temperatures $<100^{\circ} \mathrm{C}$. Extensive cracking found in a knuckle transition section of one of the 304 stainless steel vessels of the heavy-water tritium-production reactors at Savannah River Laboratories at doses below $-0.5 \mathrm{dpa}$ and temperatures $<130^{\circ} \mathrm{C}$ was attributed to prior, inadvertent sensitization heat treatment during fabrication. ${ }^{3,4}$ That conclusion was influenced by the belief at that time that radiationinduced depletion of chromium would not occur at temperatures $<130^{\circ} \mathrm{C}$. It is now known, from Kodama and from observations of radiation creep in 316 alloy at $60^{\circ} \mathrm{C}$, that considerable atomic transport can occur in austenitic steels during irradiation at $<100^{\circ} \mathrm{C}$. So the possibility for IASCC in the PCSA is real and needs to be watched. On the positive side, the stainless steel vessel of the light water-cooled Advanced Test Reactor at Idaho Falls has not displayed IASCC during more than 20 years of service. Also, a 347 stainless steel flight tube assembly removed from the High Flux Isotope Reactor (HFIR) after 5 years and a dose of -10 dpa did not suffer IASCC. ${ }^{6}$ Of course, the levels of stress, residual and applied, will be a factor. Hence, although the potential exists for IASCC in a 316 stainless steel PCSA during long-term irradiations in the ANS at $<100^{\circ} \mathrm{C}$, it might not be realized if high stresses and sensitization treatments are avoided. The service hoop stress on the PCSA

"M. Kodama, Nippon Nuclear Fuel Development Co., Ltd., Ibaraki-ken 311-13, Japan, "IASCC Susceptibility and Grain Boundary Chemistry of Austenitic Steels Irradiated at $50^{\circ} \mathrm{C}$," seminar presented to Metals and Ceramics Division, Oak Ridge National Laboratory, Aug. 4, 1995. 
because of the coolant entrance pressure of $3.7 \mathrm{Mpa}$ is estimated to be only $22 \mathrm{Mpa}$. This stress is less than one-tenth of the typical yield strength ( 250 to $300 \mathrm{Mpa}$ ) of annealed 316 steel at 25 to $100^{\circ} \mathrm{C}$. Such a low stress level might also mitigate concerns about radiation creep. ${ }^{5}$ Therefore, this report will focus on the phenomenon of radiation hardening.

Radiation hardening and associated loss in ductility are caused by accumulation of point defects (namely, vacancies, interstitial atoms, and solute atoms) generated and mediated by atomic displacements. In hard neutron spectra, the majority of the point defects are created by the more energetic neutrons $(>0.1 \mathrm{MeV})$, which elastically collide with lattice atoms, causing primary knock-on atoms, which successively displace adjacent atoms in cascadelike events. Other sources of atomic displacements are epithermal neutrons, gamma rays, and thermal neutrons. The contribution from epithermal neutrons is usually small enough to neglect. Gamma rays generate atomic displacements by energizing electrons via Compton scattering and electron-positron pair production; the electrons elastically displace the atoms. Thermal neutrons undergo absorption by metal nuclei to form isotopes or transmutation products. The low-energy $(-400 \mathrm{eV})$ recoils associated with emission of gamma rays from the isotopes cause atomic displacements. Particles emitted from transmutation reactions have much larger energies in the hundreds of $\mathrm{keV}$ range, which can cause considerable atomic displacements. The element nickel has unusually high reaction cross sections for transmutation to helium through a two-stage neutron capture sequence with thermal neutrons, ${ }^{58} \mathrm{Ni}(\mathrm{n}, \gamma)^{59} \mathrm{Ni}(\mathrm{n}, \alpha)^{56} \mathrm{Fe}$. The energies of the particles emitted from the $(n, \alpha)$ part of the reaction are $340 \mathrm{keV}$ for the ${ }^{56} \mathrm{Fe}$ atom and $4.7 \mathrm{MeV}$ for the alpha, of which a net energy of $176 \mathrm{keV}$ per neutron capture is spent as damage energy. Such damage energy is equivalent to the primary knock-on energies transferred by neutrons of several tens of $\mathrm{MeV}$. So the displacement damage from many $(n, \alpha)$ recoils in a soft neutron spectrum might be quite like that from a hard neutron spectrum.

Greenwood has developed the appropriate equations and cross sections for calculating the helium concentrations and related atomic displacements from ${ }^{59} \mathrm{Ni}(\mathrm{n}, \alpha){ }^{56} \mathrm{Fe}$ reactions in ${ }^{58} \mathrm{Ni}^{7}$ The helium production equation is

$$
C_{\mathrm{HE}}=\frac{10^{6} N_{\mathrm{HE}}}{\left.N_{0}{ }^{58} \mathrm{Ni}\right)}=\frac{\sigma_{\alpha}}{\sigma_{\mathrm{T}}}+\frac{\sigma_{\alpha} \mathrm{e}^{-\sigma_{\mathrm{T}} \phi t}}{\left(\sigma_{\gamma}-\sigma_{\mathrm{T}}\right)}-\frac{\sigma_{\alpha} \sigma_{\gamma} \mathrm{e}^{-\sigma_{\mathrm{T}} \phi t}}{\left(\sigma_{\gamma}-\sigma_{\mathrm{T}}\right) \sigma_{\mathrm{T}}},
$$

where

$C_{\mathrm{He}}=$ concentration of helium in atomic parts per million (appm),

$N_{\mathrm{He}}=$ number of helium atoms produced,

$N_{0}\left({ }^{58} \mathrm{Ni}\right)=$ initial number of ${ }^{58} \mathrm{Ni}$ atoms,

$\sigma_{\alpha}=$ spectral-averaged ${ }^{59} \mathrm{Ni}(\mathrm{n}, \alpha)$ cross section,

$\sigma_{\mathrm{T}}=$ spectral-averaged total absorption cross section of ${ }^{59} \mathrm{Ni}$,

$\sigma_{\gamma}=$ spectral-averaged ${ }^{58} \mathrm{Ni}(\mathrm{n}, \gamma)$ cross section,

$\phi=$ total flux,

$t=$ irradiation time.

In a predominantly thermal neutron spectrum where most of the neutrons have energies $<0.5 \mathrm{eV}$, the total flux and the spectral-averaged cross sections can be replaced by the $2200-\mathrm{m} / \mathrm{s}$ values, for

\footnotetext{
'P. F. Cento, Oak Ridge National Laboratory, July 27, 1995.
} 
which Greenwood gives the $2200-\mathrm{m} / \mathrm{s}$ flux $=0.8862 \times \phi_{(<0.5 \mathrm{eV})}, \sigma_{\gamma}=4.6 \mathrm{~b}, \sigma_{\mathrm{T}}=92 \mathrm{~b}$, and $\sigma_{\alpha}=11.6 \mathrm{~b}$. For helium production from the nickel in 316 alloy, Eq. (1) must be multiplied by 0.146 , the atomic fraction of natural nickel in the alloy (assuming $14 \mathrm{wt} \%$ ) and by 0.683 (the fractional abundance of ${ }^{58} \mathrm{Ni}$ in natural nickel). The thermal neutron fluxes in the PCSA are expressed as E $<0.625 \mathrm{eV}$. Taking those fluxes to be equivalent to those with $\mathrm{E}<0.5 \mathrm{eV}$ should introduce negligible error. Thus, the equation for calculating the helium concentrations in the PCSA can be reduced to

$$
C_{\mathrm{He}}=\left(0.126087-0.1327231 \mathrm{e}^{-4.6 b \phi t}+0.0066362 \mathrm{e}^{-92 b \phi t}\right) 9.9718 \times 10^{-4},
$$

where $\phi t=0.8862 \times \phi_{(\mathrm{E}<0.625 \mathrm{eV})} t$. Note that the base of the third term of the expression in the parentheses differs by one digit from the corresponding term in Eq. (2) of Greenwood's paper because of a typographical error there.

The dpa values from the ${ }^{59} \mathrm{Ni}(\mathrm{n}, \alpha)^{56} \mathrm{Fe}$ reactions are given by

$$
\mathrm{dpa}=\frac{C_{\mathrm{He}}}{567}
$$

Applying Eqs. (2) and (3) to the thermal fluences in Table 1 and using atomic displacement cross sections of 800,10 , and $1 \mathrm{~b}$ for fast neutrons $(>0.1 \mathrm{MeV})$, thermal neutrons $(n, \gamma)$, and gamma rays $(>2 \mathrm{MeV}$ ), respectively, which are reasonably good approximations for iron, yields the displacement levels in Table 2.

\begin{tabular}{|c|c|c|c|c|c|c|c|}
\hline \multirow[b]{2}{*}{ Location } & \multicolumn{5}{|c|}{ Displacements per atom } & \multicolumn{2}{|c|}{$\begin{array}{c}\text { Transmutation products } \\
\text { (appm) }\end{array}$} \\
\hline & $\begin{array}{c}\text { Fast } \\
\text { neutrons } \\
(>0.1 \mathrm{MeV})\end{array}$ & $\begin{array}{c}\text { Thermal } \\
\text { neutrons } \\
(n, y)\end{array}$ & $\begin{array}{c}\text { Gamma } \\
\text { rays } \\
(>2 \mathrm{MeV})\end{array}$ & ${ }^{59} \mathrm{Ni}(\mathrm{n}, \alpha){ }^{56} \mathrm{Fe}$ & Total & Helium & ${ }^{14} \mathrm{C}$ \\
\hline Top of adapter & $5.0 \mathrm{E}-3$ & $1.8 \mathrm{E}-1$ & $4.4 \mathrm{E}-3$ & $7.5 \mathrm{E}-1$ & $9.4 \mathrm{E}-1$ & 427 & 117 \\
\hline Upper face of flange & $7.0 \mathrm{E}-4$ & $8.8 \mathrm{E}-2$ & $1.8 \mathrm{E}-2$ & $2.2 \mathrm{E}-1$ & 3.3E-1 & 127 & 57 \\
\hline Bottom of adapter & $7.0 E-4$ & $1.8 \mathrm{E}-3$ & $8.0 \mathrm{E}-4$ & $1.4 \mathrm{E}-4$ & $3.4 \mathrm{E}-3$ & $7.7 \mathrm{E}-2$ & 1.2 \\
\hline Manifold & $7.0 \mathrm{E}-5$ & $8.8 E-5$ & $1.8 \mathrm{E}-4$ & $1.8 \mathrm{E}-5$ & $3.6 \mathrm{E}-4$ & $1.0 \mathrm{E}-2$ & $5.7 \mathrm{E}-2$ \\
\hline
\end{tabular}

Table 2. Atomic displacements and transmutation products in the PCSA

For completeness, atomic displacements were estimated for the upper epithermal neutrons, too. The appropriate fluences ranged from $1.8 \mathrm{E} 23$ at the top of the adapter to $8.8 \mathrm{E} 20$ at the manifold. Assuming a displacement cross section of $100 \mathrm{~b}$, the corresponding dpa values range from $1.8 \mathrm{E}-3$ to $8.8 \mathrm{E}-6$. These values are smaller than the corresponding dpas from other sources, and their omission from the table is of no consequence.

The ${ }^{14} \mathrm{C}$ levels in Table 2 are created by transmutation of nitrogen in the alloy by the reaction ${ }^{14} \mathrm{~N}(\mathrm{n}, \mathrm{p}){ }^{14} \mathrm{C}$ with thermal neutrons, for which the cross section is $1.83 \mathrm{~b}$. The ${ }^{14} \mathrm{C}$ values are estimated 
for an original nitrogen content of $0.1 \mathrm{wt} \%(-4000 \mathrm{appm})$. The transmutant carbon creates an interesting peculiarity. Nuclear grade 316 alloy was expressly developed with low carbon content to avoid a stress-corrosion problem; nitrogen was added to make up for the loss in strength resulting from removal of carbon. Presumably, it was not anticipated that carbon might be reinstated by transmutation of the nitrogen. However, the amount of carbon introduced by irradiation at the top of the flange (117 appm) is small in comparison to the original carbon content of the steel ( $<900 \mathrm{appm})$ and is unlikely to degrade the steel's stress-corrosion resistance.

It can be seen from Table 2 that the helium-related dpas dominate the dpa levels only in the upper portions of the unshielded adapter; at other locations the total dpa levels are relatively modest and of less concern. The situation, then, is that the $316 \mathrm{NG}$ adapter will suffer a displacement level of about $1 \mathrm{dpa}$ in its upper section, with concurrent introduction of -430 appm helium and -120 appm transmutant carbon at an irradiation temperature $<100^{\circ} \mathrm{C}$. These changes will transpire in a very soft neutron spectrum. There are no measurements of mechanical properties of 316 alloy for such conditions. There are measurements for materials irradiated in hard neutron spectra. Therefore, to predict the mechanical properties of the PCSA after 40 years of service, it is necessary to use the hard neutron data, with the implicit assumption that the atomic displacements in the PCSA will be as effective as those generated by hard neutrons. In view of the earlier description of the high recoil energy associated with the ${ }^{59} \mathrm{Ni}(\mathrm{n}, \alpha)^{56} \mathrm{Fe}$ reaction that produces most of the displacements in the PCSA, this assumption is plausible.

Almost all the mechanical properties data available for irradiated 316 steel are tensile properties. In the earlier assessment of the older-style PCSA, the property changes were predicted using generic property trend curves for austenitic steels. ${ }^{8}$ For the present assessment, tensile data specific to initially solution-annealed 316 alloy irradiated and tested at temperatures $<100^{\circ} \mathrm{C}^{9-15^{*}}$ have been compiled into the trend bands displayed in Fig. 2. The fast fluences were converted to dpa using a displacement cross section of $1500 \mathrm{~b}$. The shaded bands depict the spread in data for the yield strength (YS), ultimate tensile strength (UTS), total elongation, and uniform elongation. Individual datum points are labeled $\mathbf{y}$ for YS, $\mathbf{T}$ for UTS, $t$ for total elongation, and $\mathbf{u}$ for uniform elongation. There is considerable scatter in the data. Nevertheless, the trends are clear. In general, the YS and UTS are increased and the ductility is reduced with dose, in conformity with well-established patterns for other metals and alloys. The UTS shows the least overall response, a maximum increase of about $30 \%$, and it approaches saturation at doses above $\sim 10^{-2} \mathrm{dpa}$. The YS displays the strongest response, increasing by $-70 \%$ at $10^{-2} \mathrm{dpa}$ and continuing to about $160 \%$ increase at a doses above $-10 \mathrm{dpa}$, at which the YS and the UTS become almost coincident. Much of the change in properties happens at doses before $10^{-2}$ to $10^{-1} \mathrm{dpa}$; thereafter, the elongations remain almost constant until $\sim 10 \mathrm{dpa}$, where they begin falling markedly. Data are sparse around these knees in the elongation bands. The start of the knees correlates with almost full overlap of the YS and UTS bands and thereby represents a regime where little or no capacity remains for bulk plastic strain, and only highly localized plastic instability or cracking can prevail. In short, the knees indicate the onset of a brittle region at $-10 \mathrm{dpa}$. The upper parts of the unshielded PCSA see a dose close to $1 \mathrm{dpa}$, well below the brittle region, as indicated by the vertical line in the figure.

The role of helium in Fig. 2 is not obvious. There will be large quantities of helium in the PCSA. For the most part, the data in Fig. 2 are for materials with low helium levels, up to a few tens of appm. It is well known that the presence of a few appm of helium during irradiation can promote the formation of dislocations, cavities, and precipitates, ${ }^{16,17}$ which constitute the radiation damage

\footnotetext{
'Includes unpublished data from K. Farrell and S. T. Mahood, Oak Ridge National Laboratory.
} 


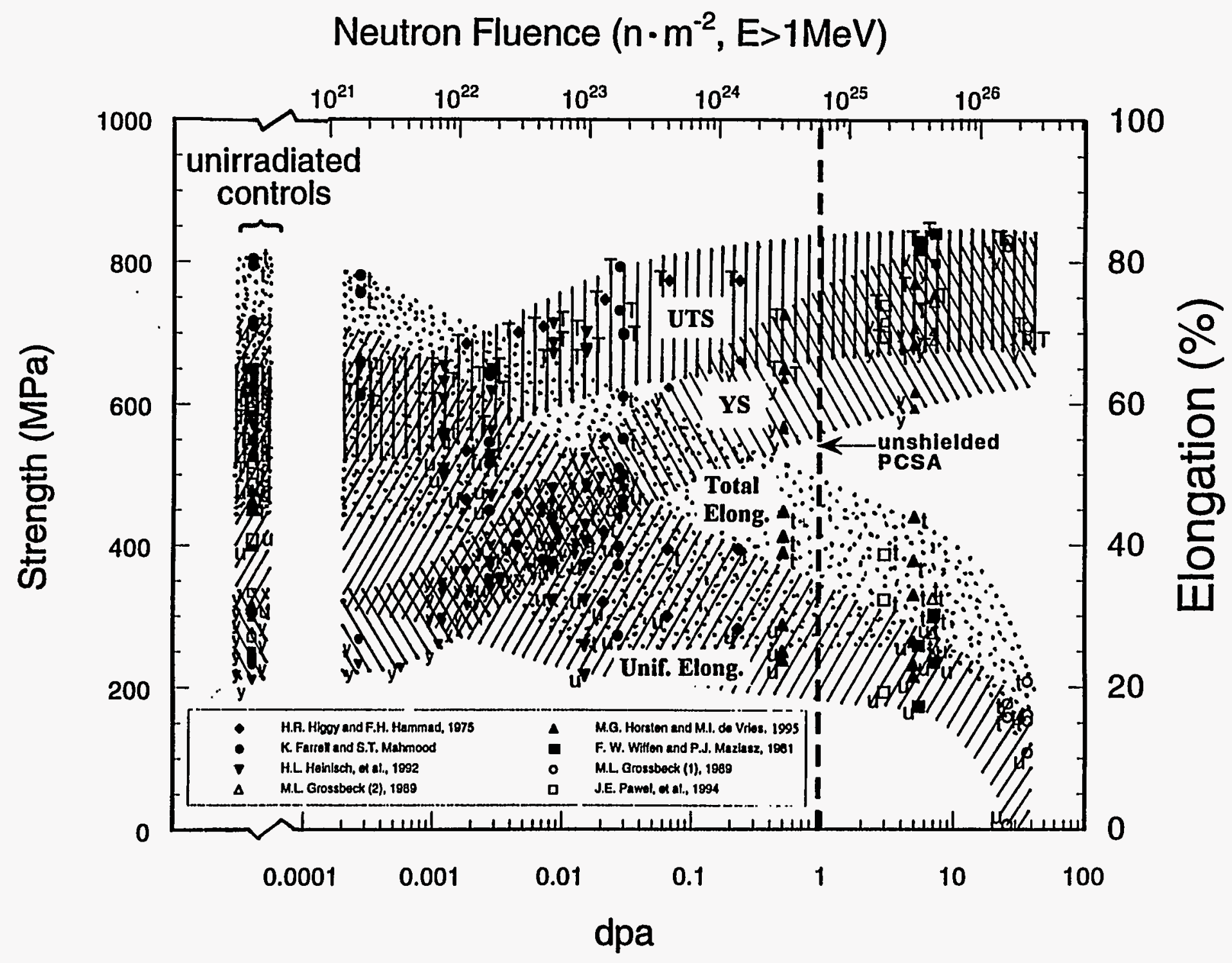

Fig. 2. Tensile properties of annealed 316 austenitic steels, neutron-irradiated and tested at $<100^{\circ} \mathrm{C}$. 
microstructure and contribute to radiation hardening. An important factor is the ratio of appm of helium to dpa. The higher the ratio, the greater the effects of helium on mediating the damage microstructure. In a hard neutron spectrum, the He/dpa ratio for 316 alloy is $<1$. For the highly irradiated parts of the PCSA, it is about 450. A high ratio implies less point defect-assisted migration of the helium and less agglomeration, which will give more hardening centers. Even without irradiation, the presence of helium (when created by decay of dissolved tritium, for example) can cause hardening and a loss of ductility and toughness. ${ }^{18,19}$ Therefore, when Fig. 2 was being prepared, it was expected that the curves would not closely depict the tensile properties of material with high helium concentrations; they would understate the degree of change in the parameters. However, some of the data in Fig. 2 were obtained from irradiations in the HFIR at locations where the He/dpa ratio is 40-50, which should be sufficiently high to reveal any outstanding contribution from the helium and should be more relevant for predicting the tensile properties of the PCSA. At the highest fluences that demark the knees in the elongation bands, all of the data are from HFIR irradiations, and the specimens contained up to several thousand appm of helium. Other HFIR data are dispersed over the full fluence range, and eliminating them does not change the shapes of the bands. So it seems that effects of moderately high levels of helium are incorporated in Fig. 2. The influence of carbon is covered, too, because the data encompass low- and high-carbon versions of 316 alloy. Hence, the trend bands should fairly predict the tensile properties of the PCSA. There is a paucity of data for the corresponding changes in fracture toughness, as seen in Fig. $3{ }^{20}$ The curve attributed to Lucas ${ }^{8}$ is a generic trend line for solution annealed, austenitic stainless steels irradiated at 290 to $430^{\circ} \mathrm{C}$. The data from Sindelar et al..$^{21}$ are for annealed 304 alloy. The data shown at $3 \mathrm{dpa}$ are from specimens irradiated in the HFIR. For a displacement dose of $1 \mathrm{dpa}$ in the PCSA, the fracture toughness will remain above $200 \mathrm{Mpa} \sqrt{\mathrm{m}}$. It is expected that fatigue crack resistance will scale with fracture toughness.

In the earlier assessment of the PCSA, the estimated displacement level at the top of the adapter was $13 \mathrm{dpa}$, which is clearly an untenable level; hence, the use of a shield to reduce the thermal fluxes was recommended. It is evident from Figs. 2 and 3 that a displacement dose of 1 dpa and reduced concerns about helium will negate that recommendation. Although the mechanical properties of annealed 316 steel are degraded by neutron irradiation at a dose of $1 \mathrm{dpa}$, the steel is not fully embrittled. Substantial ductility remains and is considered sufficient to allay fears of radiation embrittlement. There are no standard practices or universal recommended guidelines for deciding the minimum values of service-degraded mechanical properties that define safe end-of-life fluences for neutron-irradiated reactor components. The decision is left to the reactor designer. Annealed 316 stainless steel is a tough and tractable material. It does not suffer sudden ductile-to-brittle transitions like ferritic steels. Rather, under displacive irradiation it displays gradual degradation of mechanical properties in a manner predictable from Figs. 2 and 3. As can be seen, $20 \%$ uniform tensile elongation and a fracture toughness $>200 \mathrm{Mpa} \sqrt{\mathrm{m}}$ are retained at a displacement dose of $1 \mathrm{dpa}$, which should provide a satisfactory margin of safety against brittle failure. Under these circumstances, the use of a thermal neutron shield is of dubious worth, as discussed below.

\section{SHIELD EFFECTIVENESS}

Since the source of most of the damage to the most highly irradiated parts of the PCSA is thermal neutrons, the use of a thermal neutron absorber will reduce the flux of thermal neutrons on the PCSA and delay the accumulation of damage. A thermal neutron shield will keep the PCSA exposure farther away from the knee of the nil ductility region at $10 \mathrm{dpa}$ in Fig. 2 but, because of the plateau in the uniform elongation, will not offer improvements in ductility. Raising the uniform elongation above 


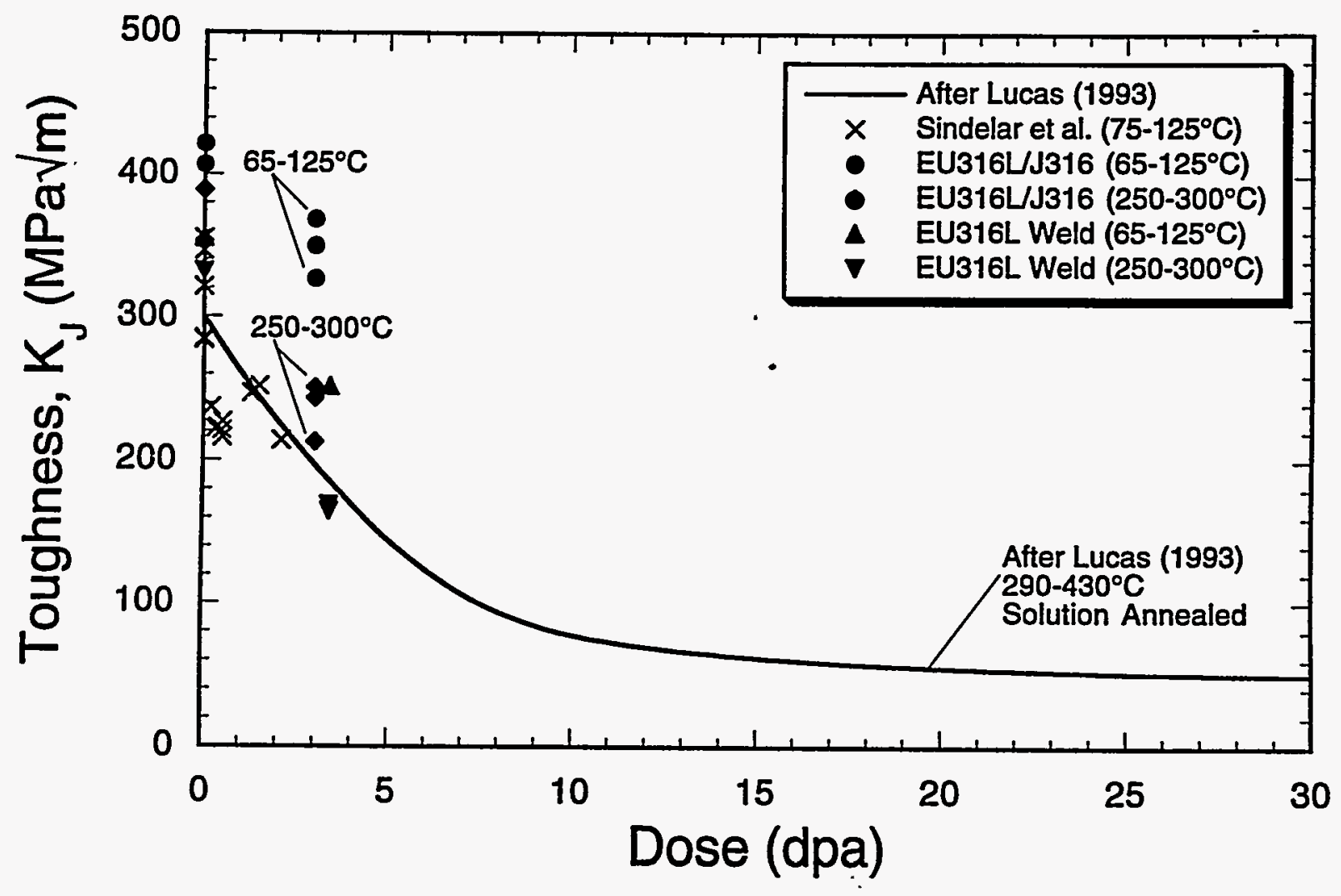

Fig. 3. Fracture toughness of neutron-irradiated 304 and 316 austenitic steels. 
the $20 \%$ value of the plateau region in Fig. 2 will require that the shield reduce the dpa level below $10^{-2}$. Figure 4 shows that a thermal neutron shield will not permit such low dpa levels. This figure illustrates the effects of thermal neutrons on the total dpa at the top of the adapter. The total is the summed atomic displacements from thermal neutron reactions, fast neutrons, and gamma rays. A thermal neutron shield (hafnium, for example) is transparent to fast neutrons, and the gamma rays it blocks are compensated for by the gamma rays it creates. Therefore, it is assumed in Fig. 4 that atomic displacements generated from fast neutrons and gamma rays would be unaffected by the shield. It can be seen that a decade reduction in thermal fluence from the unshielded fluence would reduce the dpa level to $-4 \times 10^{-2}$. A second decade reduction drops the contribution from $(n, \gamma)$ and ${ }^{58} \mathrm{Ni}(\mathrm{n}, \gamma)^{59} \mathrm{Ni}(\mathrm{n}, \alpha)^{56} \mathrm{Fe}$ reactions to $2 \times 10^{-3} \mathrm{dpa}$ but still leaves a total dpa of about $2 \times 10^{-2} \mathrm{dpa}$ because the dpas from the other sources have become dominant and will remain so despite any further diminishment in thermal neutron fluence. This conclusion, taken together with the estimation ${ }^{3}$ that a shield around the PCSA will not ease the biologically hazardous radiation fields in the subpile room, where radiation streaming down the CPBT is the major offender, suggests that such a shield is unnecessary.

\section{CONCLUSIONS}

Radiation damage in the $316 \mathrm{NG}$ alloy PCSA is less than previously expected. The maximum neutron fluence after 40 years at 0.7 duty factor is $1.8 \times 10^{26}$ thermal neutrons $\mathrm{m}^{-2}$ with a corresponding fast fluence of $6.2 \times 10^{22} \mathrm{~m}^{-2}$ ( $E>0.1 \mathrm{MeV}$ ). The resulting helium concentration and atomic displacements are -430 appm and $1 \mathrm{dpa}$, respectively. From graphs of mechanical properties of irradiated 316 alloy versus dpa, it is demonstrated that although such an exposure will degrade the mechanical properties of the PCSA, the PCSA should, nevertheless, retain a uniform tensile elongation of $20 \%$ and a fracture toughness of at least $200 \mathrm{Mpa} \sqrt{\mathrm{m}}$, which should provide adequate resistance to brittle failure. Consequently, the use of a thermal neutron shield around the PCSA is considered unnecessary.

\section{REFERENCES}

1. K. Farrell, "Radiation Effects on a Stainless Steel Primary Coolant Manifold Adapter," Attachment A in Monthly Progress Report for May 1994, ORNL/ANS/INT-5/V74, Martin Marietta Energy Systems, Inc., Oak Ridge Natl. Lab., June 1994.

2. F. X. Gallmeier et al., Analysis of the In-Vessel Control Rod Guide Tube and Subpile Room Shielding Design for the ANS Reactor, ORNL/TM-12996, Lockheed Martin Energy Systems, Inc., Oak Ridge Natl. Lab., August 1995.

3. R. L. Sindelar, N. G. Awadalla, and N. P. Baumann, Life Extension Approach to the Reactor Vessel of a Nuclear Production Reactor, DP-MS-88-143, E. I. du Pont de Nemours and Co., Savannah River Laboratory, Aiken, S.C., July 1989.

4. W. R. Kanne, Jr., "Remote Reactor Repair: GTA Weld Cracking Caused by Entrapped Helium," Weld. J. 67, 33-39 (August 1988). 


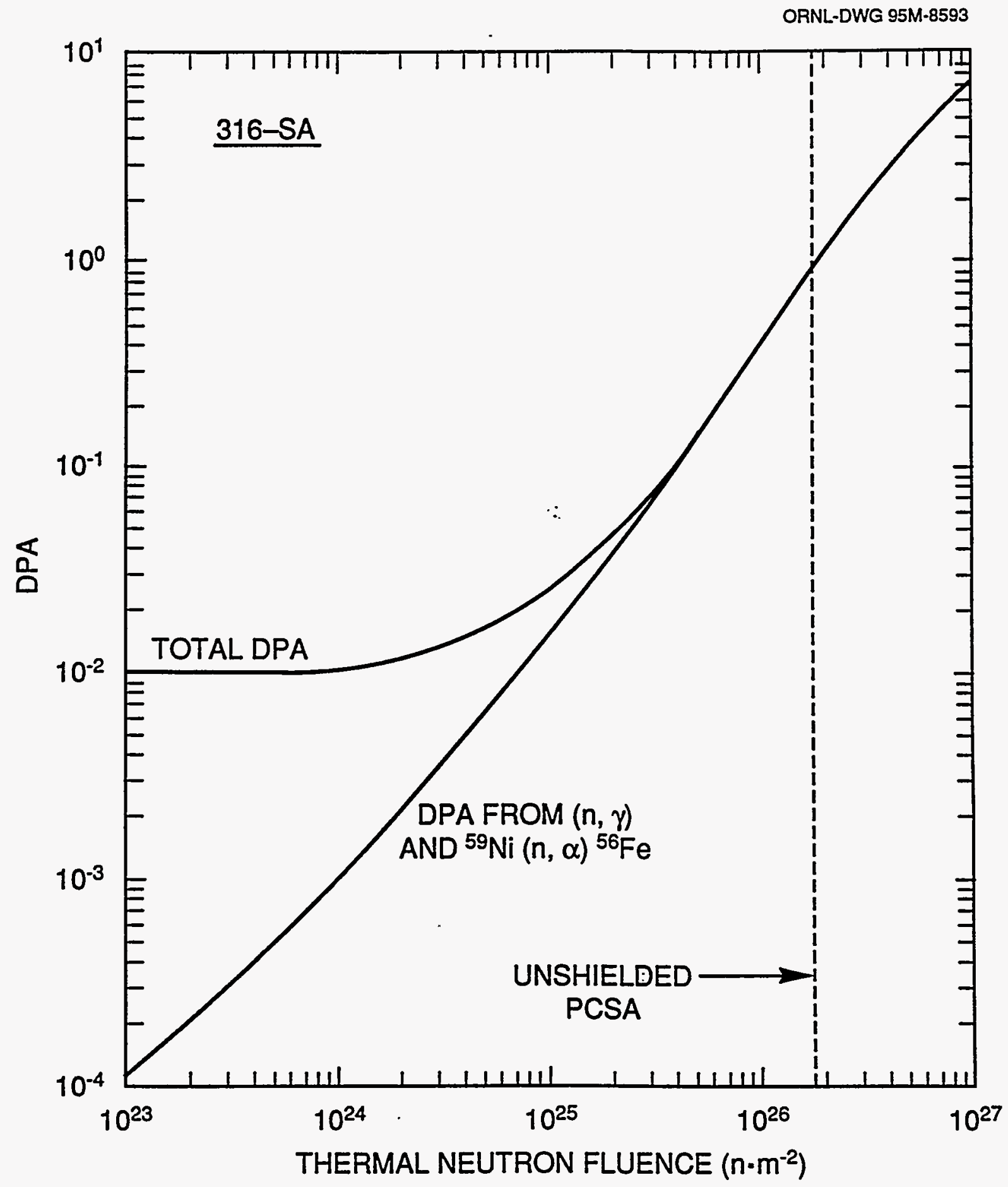

Fig. 4. Influence of thermal neutron fluence on atomic displacements at the top of the PCSA, assuming constant displacements from fast neutrons and gamma rays. 
5. M. L. Grossbeck, L. K. Mansur, and M. P. Tanaka, "Irradiation Creep in Austenitic Stainless Steels at 60 to $400^{\circ} \mathrm{C}$ with a Fusion Reactor Helium to Dpa Ratio," pp. 537-50 in Effects of Radiation on Materials: 14th International Symposium, Vol. 2, ASTM STP 1046, American Society for Testing and Materials, Philadelphia, 1990.

6. R. J. Gray et al., An Integrity Study of Type 347 Stainless Steel Tubes After a Five-Year Service in a High Flux Nuclear Reactor, ORNL/CF/85/76, Martin Marietta Energy Systems, Inc., Oak Ridge Natl. Lab., August 1985.

7. L. R. Greenwood, "A New Calculation of Thermal Neutron Damage and Helium Production in Nickel," J. Nucl. Mater. 115, 137-42 (1983).

8. G. E. Lucas, "The Evolution of Mechanical Property Change in Irradiated Austenitic Stainless Steels," J. Nucl. Mater. 206, 287-305 (1993).

9. H. R. Higgy and F. H. Hammand, "Effect of Fast Neutron Irradiation on Mechanical Properties of Stainless Steels: AISI Types 304, 316 and 347," J. Nucl. Mater. 55, 177-86 (1975).

10. M. G. Horsten and M. I. de Vries, "Irradiation Hardening and Loss of Ductility of Type 316L(N) Stainless Steel Plate Material Due to Neutron Irradiation," to be published in Effects of Radiation on Materials: 17th International Symposium, ASTM STP 1270, American Society for Testing and Materials, Philadelphia.

11. F. W. Wiffen and P. J. Maziasz, "The Influence of Neutron Irradiation at $55^{\circ} \mathrm{C}$ on the Properties of Austenitic Stainless Steels," J. Nucl. Mater. 104, 821-26 (1981).

12. H. L. Heinisch et al., "Tensile Property Changes of Metals Irradiated to Low Doses with Fission, Fusion and Spallation Neutrons," J. Nucl. Mater. 191-94, 1177-82 (1992) and supplemental details from H. L. Heinisch, Mar. 16, 1995.

13. M. L. Grossbeck, "Development of Tensile Properties for the ITER Data Base," pp. 243-57 in Fusion Reactor Materials Semiannual Progress Report for the Period Ending March 31, 1989, DOE/ER-0313/6, U.S. Dept. of Energy, Office of Fusion Energy, 1989.

14. M. L. Grossbeck et al., "Tensile Properties of Austenitic Stainless Steels Irradiated in the ORR Spectral Tailoring Experiments ORR-MFE-6 and -7," pp. 259-68 in Fusion Reactor Materials Semiannual Progress Report for the Period Ending March 31, 1989, DOE/ER-0313/6, U.S. Dept. of Energy, Office of Fusion Energy, 1989.

15. J. E. Pawel et al., "Fracture Toughness of Candidate Materials for ITER First Wall, Blanket, and Shield Structures," J. Nucl. Mater. 212-15, 442-47, (1994) and additional data from J. E. Pawel, July 1995.

16. K. Farrell et al., "Modification of Radiation Damage Microstructure by Helium," Radiat. Eff. 78, 277-95 (1983). 
17. R. E. Stoller, "The Influence of Helium on Microstructural Evolution: Implications for DT Fusion Reactors," J. Nucl. Mater. 174, 289-310 (1990).

18. A. W. Thompson, "Mechanical Behavior of Face-Centered Cubic Metals Containing Helium," Mater. Sci. Eng. 21, 41-48 (1975).

19. G. R. Caskey, Jr., D. E. Rawl, Jr., and D. A. Mezzanotte, Jr., "Helium Embrittlement of Stainless Steels at Ambient Temperature," Scr. Met. 16, 969-72 (1982).

20. D. J. Alexander et al., "Fracture Toughness of Irradiated Candidate Materials for ITER First Wall/Blanket Structures," to be published in Effects of Radiation on Materials: 17th International Symposium, ASTM STP 1270, American Society for Testing and Materials, Philadelphia.

21. R. L. Sindelar et al., "Mechanical Properties of 1950's Vintage Type 304 Stainless Steel Weldment Components After Low Temperature Neutron Irradiation," pp. 714-46 in Effects of Radiation on Materials: 16th International Symposium, ASTM STP 1175, American Society for Testing and Materials, Philadelphia, (1993). 



\section{INTERNAL DISTRIBUTION}

1. D. J. Alexander

2. D. F. Craig

3-7. K. Farrell

8. G. F. Flanagan

9. L. L. Horton

10-13. R. L. Johnson

14. L. K. Mansur

15. T. J. McManamy

16. J. E. Pawel

17. C. C. Queen

18. A. F. Rowcliffe
19. D. L. Selby

20. C. D. West

21. G. T. Yahr

22-24. Metals and Ceramics Division, Records Office

25. ORNL Patent Office

26. Central Research Library, Document Reference Section

27. Y-12 Technical Library 28-29. Laboratory Record Dept.

30. Laboratory Records, RC

\section{EXTERNAL DISTRIBUTION}

31. U.S. Department of Energy, ANS Project Office, Oak Ridge Operations Office, FEDC, MS-8218, P.O. Box 2009, Oak Ridge, TN 37831-8218.

32-33. Office of Scientific and Technical Information, P.O. Box 63, Oak Ridge, TN 37831 
